\title{
MONITORAMENTO POR CÂMERAS, INTIMIDADE DO EMPREGADO E DIREITO FUNDAMENTAL AO TRABALHO DIGNO
}

\author{
SURVEILLANCE CAMERAS BY, THE EMPLOYEE PRIVACY AND \\ FUNDAMENTAL RIGHT TO DECENT WORK
}

Aline Oliveira Mendes de Medeiros ${ }^{1}$

Rodrigo Goldschmidt ${ }^{2}$

Resumo: O presente texto tem por escopo analisar o uso do monitoramento por câmeras no ambiente de trabalho em relação à intimidade do empregado condicionado ao direito fundamental ao trabalho digno. Assim sendo, para o desenvolvimento do manuscrito, utilizou-se o método de pesquisas bibliográficas e jurisprudenciais, objetivando analisar o posicionamento teórico e prático dos tribunais acerca do tema, resultando no fato de que frente a esta colisão de direitos, efetua-se a técnica da ponderação de interesses baseada na dignidade da pessoa humana, e no equilíbrio das relações entre empregador e empregado, com isso, conclui-se que o uso de tal meio não apenas é aceito tanto pelos doutrinadores como pelo meio jurídico, como também, aconselhável para certos ambientes, desde que respeitadas algumas peculiaridades protetivas do trabalhador, e alguns limites ao empregador no uso de tal técnica.

Palavras-chave: Direito Fundamental ao Trabalho Digno; Direito do Trabalho; Monitoramento por Câmeras; Ponderação de Interesses; Dignidade da Pessoa Humana.

Abstract: The scope of this text is to analyze the use of monitoring by cameras in the workplace in relation to intimacy employee conditioning the fundamental right to decent work. Thus the method of literature and case studies and to the development of the manuscript was used, aiming to analyze the theoretical and practical positioning of the courts on the subject, resulting in the fact that the face of this collision of rights, makes the technique weighting based on human dignity interests, and the balance of relations between employer and employee, thus, it is concluded that the use of such

${ }^{1}$ Graduanda em Direito na Universidade do Oeste de Santa Catarina. Pesquisadora na área de direitos fundamentais com ênfase em segurança pública, militar e ambiental; Articulista assídua em diversas revistas jurídicas; Autora do Blog Direito em Estudo.

\footnotetext{
${ }^{2}$ Pós-Doutor em Direito pela Pontifícia Universidade Católica do Rio Grande do Sul. Doutor em Direito pela Universidade Federal de Santa Catarina. Especialista em Direito Civil pela Universidade de Passo Fundo -1998. Mestre em Direito pela Universidade Federal de Santa Catarina - 2001. Professor da Universidade do Oeste de Santa Catarina/PR.
} 
means is not only accepted by both scholars and by legal means, but also advisable to certain environments, subject to compliance with certain protective peculiarities of the worker, the employer and some limits on the use of such a technique.

Keywords: Fundamental Right to Decent Work; Labor Law; By monitoring cameras; Balancing of Interests; Dignity of the Human Person.

\section{CONSIDERAÇÕES INICIAIS}

O presente texto objetiva fazer um estudo acerca da utilização do monitoramento por câmeras no ambiente de trabalho, sob a ótica do direito fundamental ao trabalho digno. Para a obtenção do resultado pretendido, empregou-se o método de pesquisa bibliográfica.

$\mathrm{O}$ artigo inicia abordando o direito de o empregador utilizar de seu poder diretivo sobre o empregado. Para tanto, visitam-se quatro teses doutrinárias existentes acerca do assunto, dando enfoque à teoria majoritária defendida por autores como Delgado, Barros e Silva no sentido de que tal poder provém do contrato de trabalho, celebrado por meio da autonomia de vontade, concepção esta, que abrange a todas as outras teorias em seu núcleo.

Nessa linha, evidencia-se que apesar da autonomia de vontade guiar um contrato de trabalho, e proveniente do mesmo, emergir o poder diretivo do empregador, esse não se posiciona como um poder supremo, porque se encontra balizado pelos direitos fundamentais protetor do trabalhador, de forma a equilibrar estas relações, com base no princípio da dignidade da pessoa humana.

Superado esse item, tangenciam-se os principais direitos lesados nessa situação conflituosa, quais sejam, os direitos personalíssimos do empregado, mais precisamente, os direitos à intimidade e à privacidade, protegidos devido ao seu cunho valorativo, por normas do direito internacional, constitucional e infraconstitucional.

Por conseguinte, bordara-se a diretriz da dignidade humana, como elemento condizente com a aplicação direta e imediata dos direitos fundamentais nas relações privadas, aplicações estas provenientes de princípios como o da ponderação de interesses, valoração de interesses e razoabilidade. 
Por fim, abordam-se as ações afirmativas da pessoa humana como uma forma de resistência, isto é, uma forma de garantir o equilíbrio entre as relações de empregador e empregado, pautadas na ponderação de interesses e na razoabilidade voltadas para a resolução da casuística, de maneira a verificar qual decisão traria menor prejuízo para as partes envolvidas na relação contratual trabalhista.

\section{PODER DIRETIVO DO EMPREGADOR E A RELAÇÃO CONTRATUAL COM O EMPREGADO}

De acordo com o art. $2^{\circ}$ da CLT, o empregador tem o direito de admitir, assalariar, bem como, dirigir a prestação do serviço. Decorre, portanto, que ao empregador a legislação garante o poder diretivo. Porém, tal poder não é absoluto pois encontra limitações em face dos direitos fundamentais dos trabalhadores.

Neste sentido, Nascimento expressa (2003, p. 100), que tal poder de direção consiste em uma "faculdade atribuída ao empregador de determinar o modo como à atividade do empregado, deve ser exercida". No mesmo sentido, Delgado destaca (2006, p. 629):

\footnotetext{
Poder empregatício é o conjunto de prerrogativas asseguradas pela ordem jurídica e tendencialmente concentradas na figura do empregador, para exercício no contexto da relação de emprego. Pode ser conceituado, ainda, como o conjunto de prerrogativas com respeito à direção, regulamentação, fiscalização e disciplinamento da economia interna à empresa e correspondente prestação de serviços.
}

Da mesma forma, Moraes Filho salienta (apud Delgado, 2006, p. 165-166), em concordância com Russomano (apud Delgado, 2006, p. 166) que dentro da empresa o poder do empregador é soberano no que se refere às ordens de serviço.

Este poder decorre do sistema capitalista vigente, materializando-se através do direito de propriedade, que legaliza a forma hierárquica e disciplinar que o empregador possui em referência ao empregado. Assim, Delgado, (2006, p 167) destaca que por meio do poder diretivo empresarial, verifica-se que é "o empresário quem corre os riscos do negócio e, em consequência, a ele cabe a prerrogativa de ditar as ordens."

Nada obstante, existem críticas severas a tal teoria. Nesse sentido, destacam Gemignani T. e Gemignani D. (2009, p. 32) que o direito de propriedade consagrado no art. $5^{\circ}$ da $\mathrm{CF} / 88$, inc. XXII, não foi instituído e nem pode ser considerado como sendo 
de caráter absoluto, pois, conforme expressa a Carta Maior, no mencionado artigo, inciso XXIII, este poder apenas encontra justificativa se atendida a função social a qual a propriedade se subjuga, ou seja, o direito de propriedade não se sobreleva ao direito à privacidade conferida ao empregado.

Na mesma direção, Delgado (2006, p. 167) salienta que a concepção de soberania do empregador desconsidera a diferença existente nas relações servis e escravagistas frente à relação de emprego, visto que esta possui como elemento principal o empregado juridicamente livre pois, caso a tese anterior possuísse relevância jurídica indiscutível, não haveria diferença entre o poder empregatício e o poder do senhor dos escravos.

No mesmo senso, Reis (apud BARROS, p. 565-566) destaca:

(...) os defensores desta doutrina se impressionaram mais com os aspectos econômicos do que com os aspectos jurídicos que devem presidir a análise do problema. Não há dúvida de que economicamente e até que se opere uma transformação no regime capitalista em que vivemos, o patrão é o dono da empresa compreendida esta no seu todo perfeito. Mas a integração nesta dos trabalhadores não se opera pelo direito de propriedade, e, sim, pela via contratual, à semelhança das ligações entre a empresa e outros organismos da vida social. O empregador possui a empresa e, em nome desta, em relação ao elemento humano de sua execução, contrata os prestadores de serviço, os empregados.

Ademais, Silva (2013, p. 141) enfatiza que "o bem-estar comum depende cada vez mais de uma ação cooperativa e integrada de todos os setores da sociedade." Pois, "uma vez no exercício de atividade economicamente organizada, a atividade empresarial adquire relevância no ordenamento jurídico brasileiro, eis que o desenvolvimento desta atividade deve obedecer aos ditames da função social da empresa."

Da mesma forma, Simon (2000, pag. 101) assevera que em uma relação de emprego, o poder de direção do empregador não pode ser considerado incontestável. É inegável a sua limitação no que se refere aos direitos dos trabalhadores, posto que, "o poder do mando encontrará limites no exercício das liberdades públicas”.

Assim, acerca desta teoria, Barros (2007, p. 566) leciona que o poder do empregador se constitui da própria natureza empresarial, que compreende uma instituição com organização hierárquica, voltada ao interesse social da empresa, vista como um bem comum contraposto ao interesse individual. No mesmo sentido, congrega-se Mesquita (apud Delgado, 2006, p. 168) para o qual, o poder diretivo se fundamenta no interesse social da empresa, o qual: 
(...) exige uma perfeita organização profissional do trabalho fornecido por seus colaboradores a fim de se restringir um bem comum de ordem econômico-social. A ordem na organização técnica da produção e na administração interna da empresa exige uma direção nesse sentido.

No mesmo enfoque, Silva (2013, p. 142-144) denota que o proprietário é um ser social que possui o dever de aplicar as atividades empresariais na produção de uma riqueza social, em conformidade com a tutela estatal, ou seja:

A função social da propriedade está inserida na ideia de exercício do direito da propriedade, em prol dos interesses de todos (...). É uma forma de conjugar fruição individual do bem e o atendimento da sua função social visando que o titular da propriedade não abuse do seu direito.

O interesse social quer significar o empenho da empresa como incentivadora de empregos, da circulação de riquezas e serviços e arrecadadora de tributos, meios pelo os quais dá destinação social dos bens que lhe pertencem.

Por conseguinte, a questão da função social, denominada corrente institucionalista, possui previsão legal na Constituição (art. 5, inc. XXII, XXIII, XXIV, XXV, XXVI e XXIX), bem como no Código Civil (art. 421, art. 2.035 e art.2.045), e ainda em leis esparsas (Lei 6.404/76, art. 116 e por fim, Lei 11.101/05, art. 47).

Ademais, Comparato (apud SILVA, 2013, p. 145) salienta que tal tese propõe-se mais a disfarçar o abandono pelo Estado, "de toda política social, em homenagem à estabilidade monetária e ao equilíbrio das finanças públicas," do que realmente consubstanciar uma teoria, ou seja:

Quando a Constituição define como objetivo fundamental de nossa República: construir uma sociedade livre, justa e solidária (art. $3^{\circ}$, inc. I), quando ela declara que a ordem social tem por objetivo a realização do bemestar e da justiça social (art. 193), ela não esta certamente autorizando uma demissão do Estado, como órgão encarregado de guiar e dirigir a nação em busca de tais finalidades.

No que tange a questão, Delgado (2006, p. 169) enfatiza que dita tese, “dissimula a presença dos sujeitos envolvidos no (...) fenômeno do poder empregatício, através da ideia de instituição, supostamente agregadora de vontade e interesses próprios."

Em concordância, Barros (2007, p. 571) sustenta que esta concepção "possui um caráter mais político e social de que jurídico" uma vez que na rotina de empregador e do trabalhador não se percebe este interesse comunitário, perceptível na desigualdade da esfera jurídica e econômica dos sujeitos, o que demonstra que os interesses buscados pelos mesmos não se equivalem. 
Por seu turno, de acordo com a terceira corrente, é a relação de emprego que fundamenta juridicamente o poder, devido ao fato de que o Estado, como detentor do monopólio do poder disciplinar, estaria delegando aos particulares o exercício desta competência. Tal corrente denomina-se corrente publicista.

Contudo, Delgado (2006, p. 169) denota que essa tese, em consonância com a institucionalista, engloba um padrão autoritário que predominou na cultura jurídica e política ocidental no inicio do século $\mathrm{XX}$, que se mantinha coadunado ao núcleo da propriedade privada, rejeitando as disposições de participação coletiva de trabalhadores na sociedade civil e política ou empresarial, na medida em que objetivam reprimir tais tendências democratizantes.

Porém, o respectivo autor aplica a esta teoria as mesmas críticas dispersadas para a concepção anterior, em consideração de sua negação sobre a liberdade, à vontade e a dialética do poder.

Não obstante, a teoria predominante entre os doutrinadores é a doutrina contratualista, que compreende a liberdade e a vontade das partes como predominantes ao poder empregatício, já que é o contrato de trabalho que confere ao empregador o direito de utilizar seu poder empresarial, enquanto ao trabalhador irrompe-se a obrigação de prestar determinada atividade e atender as determinações do empresário quanto à maneira de prestar estas funções.

Destarte, esta relação é regida também por normas de ordem pública, tendentes a atenuar o desequilíbrio existente entre as partes, por meio da limitação de vontade das mesmas, pautadas nos direitos fundamentais.

Assim, para Delgado (2006, p. 172), outro fator relevante consiste no pacto de vontades (expresso ou tácito) como elemento originário da relação de emprego, a qual importa em um conjunto complexo de direitos e deveres integrantes de ambas as partes, que se unifica ao poder empresarial interno. Em complemento, o aludido autor destaca que devida a sua amplitude essa teoria comporta qualquer situação historicamente experimentada pela relação de emprego, sendo então a concepção que possui maior aceitação entre os doutrinadores.

Além disso, convém destacar que inexiste poder soberano por parte do empregador, indiferente de qual teoria que se venha a adotar, pelo motivo de que os trabalhadores 
possuem seus direitos reservados através dos preceitos fundamentais, os quais encontram essência basilar na dignidade humana, princípio nuclear de toda e qualquer relação jurídica, cuja amplitude e abrangência merece desenvolvimento em item próprio, como forma de valorizar e especificar seu conteúdo.

\section{O PRINCÍPIO DA DIGNIDAdE DA PESSOA HUMANA NO QUE REPORTA AS RELAÇÕES TRABALHISTAS}

Contextualizando a temática da dignidade da pessoa humana, em outro texto destacamos:

O Direito, de igual modo, surgiu da necessidade de regular as relações entre os homens, mantendo ou promovendo um equilíbrio de forças entre os mais diversos interesses e, com esse objetivo, vem se desenvolvendo ao longo do tempo, com sucessos e retrocessos.

O que importa aquilatar é que o homem e a sua dignidade constituem temas fundamentais, em torno dos quais os ramos do saber (...) se desenvolvem e se relacionam. (GOLDSCHMIDT, 2009, p. 19)

Castilho (2011, p. 138), por seu turno, destaca que o princípio da dignidade humana abarca um dos principais conjuntos de direitos, ou seja, os direitos humanos, que abrangem as legalidades que não possuem expressão nas Constituições, em decorrência de que, a partir de sua positivação na Carta, os mesmos passam a denominar-se direitos fundamentais.

Da mesma forma, Matínez (2004, p. 19) dispõe:

El término 'derechos humanos' es sin duda uno de los más usados en la cultura jurídica actual, tanto por los científicos y los filósofos que se ocupan del hombre, del Estado y del Derecho, como los ciudadanos. No en vano se puede decir que es a idea de derechos humanos tiene un significado similar al que tuvo en los siglos XVII y XVIII la de Derecho natural. Por su función reguladora de la legitimidad de los sistemas políticos y de los ordenamientos jurídicos, y por la convicción de muchos seres humanos de que constituyen una garantía para su dignidad y un cauce (el principal), para su libertad y su igualdad, la comprensión adecuada de los derechos es una tarea teórica de gran alcance práctico. ${ }^{1}$

Notas de Rodapé:

${ }^{1}$ Tradução livre: O termo "direitos humanos" é sem dúvida um dos mais utilizados na cultura jurídica de hoje, tanto por cientistas e filósofos preocupados com o homem, o estado e a lei, como pelos cidadãos. Sem os quais se pode dizer que é uma idéia dos direitos humanos semelhante ao que foi nos séculos, XVII e XVIII, o significado da lei natural. Na função reguladora da legitimidade dos sistemas políticos e ordenamentos legais, e pela crença de que muitos seres humanos buscam uma garantia para a 
Com olhar crítico, Alexy (2002, p. 15-29) enfatiza que "essas transformações dos direitos humanos em direitos positivos nunca podem ser consideradas suficientes por si mesmas, ou seja, definitivas." Devido ao fato de que, as mesmas não consistem apenas em "esforços para dar forma institucional, proteção pelo direito positivo, a algo que somente pode ser válido por causa de sua correção."

Por consequência, prossegue o mencionado autor, necessita-se considerar que essas prerrogativas "devem ser definidas como direitos que foram estabelecidos formalmente em uma constituição com a intenção de transformar os direitos humanos em direitos positivos." O que não significa dizer que tal intenção tenha sido concretizada de maneira suficiente, em razão de que, na aplicação da lei ao caso concreto, o juiz deve analisar e ponderar sobre os interesses, de maneira a concretizar e efetivar os direitos fundamentais de forma satisfatória.

Neste sentido, destaca Dworkin (2005, p. 17-124):

Os juízes não são eleitos nem reeleitos, e isso é sensato porque as decisões que tomam ao aplicar a legislação tal como se encontra devem ser imunes ao controle popular. Mas decorre daí que não devem tomar decisões independentes no que diz respeito a modificar ou expandir o repertório legal, pois essas decisões somente devem ser tomadas sob o controle popular.

Proponho os dois seguintes princípios de atuação justa no governo. Primeiro qualquer decisão política deve tratar todos os cidadãos como iguais, isto é, como tendo direitos iguais a interesse e respeito. (...). O segundo princípio refere-se à equidade de sujeitarem-se a compromissos abertos, justos quando adotados.

Isso acarreta dizer que ao juiz apenas é lícito julgar por meio do princípio da igualdade, em conformidade com o art. $5^{\circ}$, caput da Constituição Federal de 1988, o qual expressa que, "todos são iguais perante a lei, sem distinção de qualquer natureza, garantindo-se aos brasileiros e aos estrangeiros residentes no País, a inviolabilidade do direito à (...) igualdade”.

Além de que, por meio do segundo princípio, percebe-se um simples desdobramento do princípio anterior, no sentido de que, “o julgamento sob a regra estabelecida não é o momento de tratá-lo de outra forma, senão como igual", conforme as palavras do respectivo autor (obra citada, p. 125). Assim, como meio de igualar situações distintas

sua dignidade e um canal (o principal), por liberdade e igualdade, assim fazer um entendimento adequado sobre direito é uma tarefa teórica de grande significado prático. In: MARTÍNEZ, Gregoria Peces - Barba. Lecciones de Derechos Fundamentales. Madrid, Editorial Dykinson, 2004, p. 19. 
como a do empregador e do empregado é que urge utilizar-se do princípio da dignidade humana.

Nessa linha, o citado autor Dworkin (2005, p 123) enfatiza:

Dignidade vem do latim dignitas, que dizer honra, virtude. A dignidade da pessoa humana está fundada no conjunto de direitos inerentes à personalidade da pessoa (liberdade e igualdade) e também no conjunto de direitos estabelecidos para a coletividade (sociais, econômicos e culturais). Por isso mesmo, a dignidade da pessoa não admite discriminação, seja de nascimento, sexo, idade, opiniões ou crenças,classe social e outras. A dignidade não pode ser definida como a superioridade de um homem sobre o outro, mas sim como a superioridade da pessoa sobre outros seres que não são dotados de razão.

A dignidade é um valor em si mesma. E é dever do Estado garantir as condições mínimas de existência propiciando aos indivíduos uma vida digna.

Destarte, em outro estudo (GOLDSCHMIDT, 2009, p. 59) afirmamos que o princípio em questão possui forte influência na esfera jurídica, inclusive no Direito do Trabalho, pois tal concepção coloca o homem como sujeito central no sistema, enfatizando ao aplicador do direito, a "diretriz hermenêutica inarredável” de que é o capital quem "está a serviço do homem, e não o contrário."

Neste ínterin, cita-se Barbagelata (1995, p. 13-14): “El trabajo no debe ser considerado simplemente como una mercancía o como un artículo de comercio," expresa un claro propósito que debe servir de guía al legislador y al intérprete y, al misto tiempo, reivindica la autonomía del Derecho del Trabajo respecto de la Economía."2

Com efeito, a expressão dessa ideia, no mundo do trabalho, encontra exemplo na limitação da jornada de trabalho em oito horas, visando impedir a exploração da mão de obra de forma desregrada, no sentido de que o trabalho não é uma mercadoria, como atualmente ainda é tratado, o que reporta ao equilíbrio que deve-se impor nas relações entre empregado e empregador, conforme adverte Grandi (1997, p. 206):

La tensión irresoluta entre trabajo-objeto y trabajo-sujeto continúa recorriendo los itinerarios, siempre más retorcidos, de un derecho del trabajo,

\footnotetext{
${ }^{2}$ Tradução livre: "O trabalho não deve ser considerado apenas como uma mercadoria ou como um artigo de comércio", expressa um propósito claro que deve orientar o legislador e o intérprete e o tempo misto, reivindicou a autonomia do direito do trabalho em relação à economia." BARBAGELATA, Hector-Hugo. El particularismo del derecho del trabajo. Montevideo/Uruguai: Fundacíon de Cultura Universitaria, 1995. (Grifos do autor).
} 
cuyo futuro no está asegurado. Precisamente, para nuestra fortuna, el trabajo no es más una mercancía; está categóricamente prohibido en la declaración de Filadelfia. Se da el caso, sin embargo, que el trabajo, bajo muchos cielos, continúa siendo tratado como si lo fuese. ${ }^{3}$

Da mesma forma, Castilho (2011, p. 137) destaca a dignidade como possuidora de um valor em si mesma, sendo por tanto "dever de o Estado garantir as condições mínimas de existência propiciando aos indivíduos uma vida digna."

Por seu turno, Alexy (2013, p. 71) esclarece que um direito humano se caracteriza por cinco prioridades:

A primeira é a universalidade. $\mathrm{O}$ beneficiário ou titular de um direito humano é todo ser humano quanto ser humano. (...). A segunda prioridade dos direitos humanos é o caráter fundamental de seu objeto. Os direitos humanos não protegem todos os tipos de condições de bem-estar, mas apenas as capacidades, interesses e necessidades básicas. (...). A terceira prioridade (...) é a abstração. (...) A distinção entre direitos humanos enquanto direitos abstratos e sua aplicação em um caso concreto será de extrema importância para a questão da existência dos direitos humanos. (...) a quarta prioridade dos direitos humanos é a moralidade. Um direito é moralmente válido se puder ser justificado contra cada um e todos aqueles que estão aptos a tomar parte de um discurso racional. Nesse sentido, a validade moral é uma validade universal. A universalidade da estrutura dos direitos humanos enquanto direitos de todos contra, em princípio todos, é então complementada pela universalidade da validade. (...). 'A existência dos direitos humanos se expressa em sua justificabilidade, e em nada mais. ' (...) A quinta prioridade dos direitos humanos é a prioridade. Direitos humanos quanto direitos morais não podem ser invalidados por regras de direito positivo. Pelo contrário os direitos humanos são Standards para avaliar o direito positivo.

Em concordância, Tramontina e Hahn (2013, p. 150), definem a vontade como sendo "a capacidade de agir em concordância com as leis", assim, conforme Kant (apud TRAMONTINA e HAHN, 2013, p. 150), "só um ser racional tem a capacidade de agir segundo representação de leis, isto é, seguindo princípios, ou: só ele tem uma vontade. Como para derivar as ações das leis é necessário à razão, a vontade não é outra coisa senão razão prática.”

\footnotetext{
${ }^{3}$ Tradução livre: "A tensão insolúvel entre trabalho-objeto e trabalho-sujeito continua recorrendo os itinerários, sempre mais retorcidos, de um Direito de Trabalho, cujo futuro não está assegurado. Precisamente, para nossa sorte, o trabalho não é mais uma mercadoria; tal é proibido categoricamente na Declaração da Filadélfia. Se dá o caso, todavia, que o trabalho, em baixo de muitos céus, continua sendo tratado como se fosse". GRANDI, Mario. El trabajo no es uma mercancia: reflexiones akmargen de uma formula para volver a meditar. In: Estúdios em homenajeal Prof. Héctor-Hugo Barbagelata. Montevideo-Uruguai: Fundación de Cultura Universitária, 1997.
} 
Por consequência, os respectivos autores salientam que, "um corpo que cai, cai segundo a lei, mas não é capaz de representar a lei. A representação da lei somente é possível em um ser racional.”

Tendo isso em conta, Hooft (2004, p. 269) enfatiza:

(...) no cabe ninguna vacilación o duda a la altura del tempo histórico que vivimos. La dignidad de la persona es el fundamento de todos sus derechos. Es su valor fundente. Así lo reconocen las declaraciones universales, los pactos regionales, las constituciones de los Estados, sus códigos civiles. En este valor se sustentan los derechos a la libertad, a la identidad, a la igualdad, a la salud, todos ellos gravemente comprometidos en el caso bajo comentario. ${ }^{4}$

Por conseguinte, percebe-se que a autonomia coaduna-se com a racionalidade, assim, conforme Kant (apud TRAMONTINA e HAHN 2013, p. 166), “o ser humano é autônomo porque é racional e é racional por ser autônomo", ou seja, o que transforma "o ser humano em um fim em si mesmo é a sua racionalidade", o que consiste em dizer que a dignidade de um ser humano, "reside no fato de ser racional". Logo, estes seres racionais, que exercitam dupla função, como "membros e legisladores, nunca podem ser usados como fim."

De acordo com este entendimento, torna-se lícita a aplicação ampliativa dos direitos fundamentais em proteção ao trabalhador, questão que será amplamente discutida no item cinco (5) deste estudo. Não obstante, salienta Hooft (2004, p. 71):

(...) la categorización del hombre como persona; en esta visión acorde con un personalismo ético, se reconoce en cada hombre un fin, un sujeto, un valor, una dignidad inalienable, en una perspectiva incompatible con una visión meramente utilitarista, materialista, o biológica del hombre, que de hecho o de derecho lo reduzca a objeto, medio o instrumento al servicio de otros fines. A ese respecto los documentos examinados contienen una verdadera afirmación ontológica y una orientación axiológica de la que deviene al reconocimiento de todo hombre como sujeto de derechos fundamentales como "inherentes." 5

\footnotetext{
${ }^{4}$ Tradução Livre: não pode haver hesitação ou dúvida para combinar com o ritmo histórico vivo. A dignidade da pessoa é o fundamento de todos os direitos. É o seu valor de fluxo. Isto é reconhecido pelas declarações universais, acordos regionais, constituições dos Estados, os seus códigos civis. Valorizamos os direitos à liberdade, identidade, igualdade, saúde baseiam-se, extremamente comprometidos no caso em análise. In: HOOFT, Pedro Federico. Bioética y derechos humanos. $1^{\mathrm{a}}$ ed. Buenos Aires: Depalma, 2004, p. 269.
}

${ }^{5}$ Tradução Livre: (...) A categorização do homem como uma pessoa; nessa visão consistente com um personalismo ético, é reconhecido em cada homem um último, um propósito, um valor, uma dignidade inalienável, numa perpendicular incompatível com uma visão puramente utilitária, biológica, materialista ou o homem, de fato ou de direito reduzindo-o a objeto, meio ou instrumento para outros 
Destarte, de acordo com Martins, Mendes e Nascimento, (2012, p. 88) a atuação estatal deve ser envolvida por práticas de cidadania multidimensional e pluralista, baseadas na concretização dos direitos fundamentais, pois, o que legítima o poder estatal é a solidariedade, pautada na dignidade da pessoa humana como um valor indispensável e como finalidade fundamental de sua atuação.

Da mesma forma, enfatiza Branco (2012, p. 57), que a Constituição pode ser resumida através de um conjunto de proteção e promoção de valores, que emergem do núcleo basilar denominado dignidade da pessoa humana, de forma a materializá-la na sociedade.

Por corolário, verifica-se na doutrina de Sarlet (2004, p. 110), que:

O princípio da dignidade da pessoa humana impõe limites à atuação estatal, objetivando impedir que o poder público venha a violar a dignidade pessoal, mas também implica (numa perspectiva que se poderia designar de programática ou impositiva, mas nem por isso destituída de plena eficácia) que o Estado deverá ter como meta permanente, proteção, promoção e realização concreta de uma vida com dignidade para todos, podendo-se sustentar, na esteira da luminosa proposta de Clèmerson Clève, a necessidade de uma política de dignidade da pessoa humana e dos direitos fundamentais.

Nesse contexto é que se legitima e viabiliza a existência de direitos à intimidade e à privacidade do empregado, mesmo estando subordinado ao empregador no âmbito do contrato de trabalho, como se demonstrará a seguir.

\section{DIREITOS DA PERSONALIDADE: DIREITOS À INTIMIDADE E A PRIVACIDADE DO EMPREGADO}

Os direitos da personalidade possuem proteção a nível internacional, como forma de limitar a atuação do Estado e da Sociedade em face do particular. Com efeito, de acordo com o artigo 12 da Declaração Universal dos Direitos do Homem (citar, em nota de rodapé, um site onde possa ser obtido o texto integral da presente Declaração), de 1948, "Ninguém será sujeito à interferência em sua vida privada, em sua família, em seu lar ou em sua correspondência, nem a ataque à sua honra e reputação. Todo ser humano tem direito à proteção da lei contra tais interferências ou ataque.”

fins. O exposto neste documento contém uma afirmação verdadeira ontológica e axiológica, uma orientação que se torna o reconhecimento de cada pessoa como sujeito de direitos fundamentais como "inerente".HOOFT, Pedro Federico. Bioética y derechos humanos. $1^{\text {a }}$ ed. Buenos Aires: Depalma, 2004, p. 71. 
No mesmo sentido, a Constituição brasileira, no art. 5, inc. X, estabelece que "são invioláveis a intimidade, a vida privada, a honra e a imagem das pessoas, assegurado o direito a indenização pelo dano material ou moral decorrente de sua violação,”. Na mesma direção, reforçam as leis infraconstitucionais, como se percebe no art. 21 do Código Civil brasileiro, "a vida privada da pessoa natural é inviolável, e o juiz, a requerimento do interessado, adotará as providências necessárias para impedir ou fazer cessar ato contrário a esta norma."

A respeito, Sarmento (2008, p. 102) denota que "a personalidade mais do que um direito é um valor - o mais importante do ordenamento, diga-se de passagem -, que se irradia e penetra por todos os campos do Direito, público ou privado."

Por outro lado, Barros (1997, p. 172) salienta que devido à omissão da legislação trabalhista acerca do assunto, as intromissões na vida privada do empregado a cada dia se agravam, principalmente com o advento da utilização tecnológica no ambiente de labor, necessitando, com urgência, de expressão positiva acerca da questão, como forma de proteger os direitos do empregado.

Assim sendo, analisando-se as normas atinentes, evidencia-se que qualquer investida desproporcional sobre a área de proteção garantida pela Norma Maior é ilegítima, seja por meio de monitoração de e-mails, ou por vídeo monitoramento, pois se procura limitar a interferência da sociedade, em reconhecimento e resguardo da personalidade do indivíduo, em extensão ao direito da dignidade da pessoa humana, expresso no art. 1, inc. III da Carta Magna, conforme discorrido no item anterior.

A ideia de vida privada compreende meios exclusivos de convivência e troca de informações com terceiros, tal direito de privacidade existe como forma de proteger assuntos de cunho pessoal, que não interessam a comunidade em geral, e cuja pessoa prefere deixar a cunho reservado dos demais.

Neste sentido, dispõe Pontes de Miranda (apud MORAES, 2013 p. 129), que um direito a intimidade, ainda que não se trate de tema de confidencialidade, nunca perde o caráter de absoluto, pois não pode ser alienado e nem é renunciável, exceto se estiver relacionado à vida pública de uma pessoa, em conformidade com o art. 11 do CC/2002. 
Ademais, o Código Civil Francês (apud SZANIAWSKI, p. 293) coadunado às jurisprudências dos respectivos tribunais, desenvolveram limites na vida privada, como se vê adiante:

(...) tudo aquilo que concerne à vida amorosa, à vida familiar, aos recursos financeiros de uma pessoa, aos aspectos não públicos de sua vida profissional, a suas atividades de lazer, tudo o que se encontra geralmente do lado externo das fronteiras da vida privada, a parte da vida da pessoa que se desenrola necessariamente na presença do público e de sua participação na vida pública da comunidade.

Por conseguinte, Barros (1997, p. 21) destaca que "Esse direito, embora possa implicar, quando violado, pagamento de indenização, não está relacionado com a condição social ou com o patrimônio dos indivíduos. Seu fundamento é a liberdade individual." Visto que o mesmo relaciona-se diretamente, com os direitos humanos que, conforme Moraes (2013, p. 39), formam o conjunto de direitos e garantias, que possuem como pilar a dignidade da pessoa humana, "por meio de sua proteção contra o arbítrio do poder estatal e o estabelecimento de condições mínimas de vida e desenvolvimento da personalidade humana."

As garantias à intimidade e à privacidade possuem natureza jurídica em um direito fundamental de defesa, um direito subjetivo, inseparável da pessoa humana. Ademais, no tópico, Sarlet (2004, p. 62), salienta:

(...) a qualidade intrínseca e distintiva reconhecida em cada ser humano que o faz merecedor do mesmo respeito e consideração por parte do Estado e da comunidade, implicando, neste sentido, um complexo de direitos e deveres fundamentais que assegurem a pessoa tanto contra todo e qualquer ato de cunho degradante e desumano, como venham a lhe garantir as condições existenciais mínimas para uma vida saudável, além de propiciar e promover a sua participação ativa e co-responsável nos destinos da própria existência e da vida em comunhão com os demais seres humanos.

Enfatiza-se que, a personalidade, encontra garantia e proteção no princípio da dignidade humana, este por sua vez, localizando-se no ápice do ordenamento jurídico, irradiando-se para todas as demais normas, que apenas poderão ser aplicadas se estiver em conformidade com suas diretrizes, pois que, em conformidade com Tepedino (1999, p. 50) os direitos da personalidade (direitos individuais) e os direitos humanos, são inseparáveis, pelo que, "a pessoa, à luz do sistema constitucional, requer proteção integrada que supere a dicotomia do direito público e direito privado e atenda à cláusula geral fixada pelo texto maior, de promoção da dignidade humana." 
Desta forma, os direitos da personalidade, compreendem um núcleo mínimo assegurador da dignidade da pessoa humana, sob pena de incorrer em ilícito, em virtude de que, na promoção e na aplicação de qualquer norma, deve-se priorizar pela proteção integral do homem, pois a intimidade deve ser considerada como a expressão de um valor da pessoa humana.

Nessa senda, Mallet (2004, p. 1309), adverte acerca da lacuna na CLT quanto à proteção da personalidade do trabalhador, que apenas se viabiliza de forma esparsa, devido à tendência patrimonial na qual a norma em tela foi promulgada:

A lacuna, própria da época em que editada a CLT, decorre da visão reducionista do legislador, que tratou da relação de emprego como se nela as obrigações das partes se restringissem à prestação do trabalho pelo empregado, de um lado, e ao pagamento da remuneração pelo empregador, de outro lado. Tudo ficou limitado ao plano meramente patrimonial, o que se mostra tanto mais injustificável quanto é certo que, sendo o empregado, sempre e necessariamente, pessoa física (art. $3^{\circ}$, da CLT), os direitos de personalidade encontram-se inevitavelmente em causa em todo e qualquer contrato de trabalho.

De tal modo, como forma de elucidar tal conflito, propõe-se o preenchimento destas lacunas por meio do direito comum, principalmente através do Código Civil. Contudo, impende destacar, que não é a quantidade de leis que expressa à qualidade e efetividade da proteção da personalidade do empregado. O desafio, no caso, é efetuar a devida interpretação das normas já existentes, com base na luz dos princípios constitucionais, em respeito aos direitos fundamentais e direitos humanos, utilizando-se da técnica da ponderação de interesses.

Assim, será possível aos Tribunais integrar os espaços existentes, formando jurisprudência com capacidade de direcionar, sob o enfoque constitucional, os meios mais adequados de agir, em conformidade e efetivação dos direitos fundamentais da pessoa humana, acerca das diversas situações que surgem no cotidiano tendentes a vulnerabilizar ou ameaçar a intimidade e a privacidade das pessoas.

Tangenciados, por um lado, os direitos de propriedade do empregador, e, por outro, os direitos à intimidade e à privacidade do empregado, que compreendem direitos fundamentais individuais, cabe neste instante, discorrer sobre a incidência destes direitos no que concernem as relações trabalhistas. 


\title{
5. APLICAÇÃO DIRETA E IMEDIATA DOS DIREITOS FUNDAMENTAIS NAS RELAÇÕES PRIVADAS
}

No que tange a aplicação dos direitos fundamentais nas relações privadas, Martínez (2004, p. 344) evidencia:

\begin{abstract}
$\mathrm{Si}$ acudimos a hora al tenor de las normas que regulan derechos y analizamos el ámbito central de su validez, de acuerdo con el sentido común y con el análisis de la práctica jurídica, llegaremos a la conclusión de que muchos son derechos pensados también, e incluso principalmente, para las relaciones entre particulares. No se debe olvidar además que los derechos se fundamentan y enraízan en los valores superiores y éstos abarcan todo el Ordenamiento, y no solo las relaciones de Derecho público. ${ }^{6}$
\end{abstract}

Conforme Sarmento (2008, p. 203), os direitos fundamentais conferem proteção ao indivíduo contra o ente estatal, no entanto, a economia capitalista e o crescimento de entes não estatais, como as empresas ou associações, tornaram-se uma ameaça ainda maior que a proveniente do próprio Estado, exigindo, por tanto, que o enfoque destes direito passe a conceder proteção aos entes privados, como forma de garantir a proeminência dos direitos do homem, assim:

Estes, que até então eram apenas titulares de direitos humanos, oponíveis em face do Estado, assumem agora, em determinados contextos, a condição de sujeitos passivos de tais direitos. Se a opressão e a injustiça não provêm apenas dos poderes públicos, surgindo, também, nas relações privadas travadas no mercado, nas relações laborais, na sociedade civil, na família, e em tantos outros espaços, nada mais lógico do que, estender a estes domínios, o raio de incidência dos direito fundamentais, sob pena de frustração dos ideais morais e humanitários em que eles lastreiam.

No mesmo sentido, destaca Stuart Mill (2006, p. 200), que a sociedade possui uma capacidade de tiranizar, com uma crueldade ainda maior que a do Estado, em vistas de que, a comunidade social poderia praticar um despotismo social, violando princípios basilares dos direitos humanos, incapacitando o indivíduo de qualquer forma de evasão, "penetrando muito mais profundamente nos pormenores da vida, e escravizando a própria alma."

Assim sendo, de acordo com Martínez (2004, p. 347):

\footnotetext{
${ }^{6}$ Tradução Livre: Se nos voltarmos agora para a formulação das regras que regem os direitos e analisar a área central da sua validade, de acordo com o senso comum e com análise da prática jurídica, chegar à conclusão de que muitos direitos são projetados também, e até principalmente nas relações entre particulares. A pessoa também não deve esquecer que os direitos são fundados e enraízam em valores mais elevados e eles abrangem a Portaria, e não apenas as relações de direito público. In: MARTÍNEZ, Gregoria Peces-Barba. Lecciones de Derechos Fundamentales. Madrid, Editorial Dykinson, 2004, pag. 344.
} 
(...) El principio general de validez de las normas de derechos fundamentales em las relaciones privadas, si es indubitado, debe ser analizado em el caso concreto, ponderando las circunstancias y los bienes y princípios próprios del derecho privado, com el derecho fundamental concernido. $^{7}$

Ademais, Mello (apud Marmelstein, 2013 p. 116) salienta acerca da necessidade de proteger os direitos fundamentais, até para a manutenção de um Estado Democrático de Direito, já que são nestes direitos que tal sistema se fundamenta, necessitando haver uma ponderação de interesses entre a aplicação dos direitos fundamentais em conformidade com os demais princípios.

Em concordância, Novaes (apud MARMELSTEIN, 2013, p. 100) destaca que, “o direito fundamental só cede, se o Estado for capaz de encontrar uma justificação de peso, intrínseco, indiscutível; a simples vontade da maioria democrática, não é suficiente para justificar a restrição.”

Neste enfoque, Pereira (2006, p. 116) denota que a incidência dos direitos fundamentais nas relações privadas possui justificativa no fato de que ambos os sujeitos são titulares de direitos fundamentais, formando um complexo sistema de afirmativas e deveres, que delimitam-se e condicionam-se entre si. Acerca deste assunto, Alexy (2013, p. 300) destaca que, frente a uma colisão de direitos, será necessário proceder de forma a efetuar uma ponderação entre os valores debatidos. Da mesma forma, posiciona-se Lenza (2011, p. 115), para o qual:

(...) poderá o magistrado deparar-se com inevitável colisão de direitos fundamentais, quais sejam, o princípio da autonomia de vontade privada e da livre iniciativa de um lado... e o da dignidade da pessoa humana e da máxima efetividade dos direitos fundamentais (art. $1^{\circ}$, inc. III), de outro. Diante dessa 'colisão', indispensável será a 'ponderação de interesses' a luz da razoabilidade e da concordância prática ou harmonização. Não sendo possível a harmonização, o Judiciário terá que avaliar qual dos interesses deverá prevalecer.

Por conseguinte, Mendes (2012, p. 300), assevera:

Não se pode olvidar, por outro lado, que as controvérsias entre particulares, com base no direito privado, hão de ser decididas pelo Judiciário. Estando a jurisdição vinculada aos direitos fundamentais, parece inevitável que o tema constitucional, assuma relevo tanto na decisão dos

\footnotetext{
7 Tradução Livre: (...) O princípio geral de validade das regras de direitos fundamentais nas relações privadas, se é inquestionável, deve ser utilizado no caso, considerando-se as circunstâncias e as propriedades e princípios PROPRIOS de direito privado, o direito fundamental com preocupado... In: MARTÍNEZ, Gregoria Peces-Barba. Lecciones de Derechos Fundamentales. Madrid, Editorial Dykinson, 2004, p. 347.
} 
tribunais originários, como no caso de eventual pronunciamento da Corte Constitucional.

Destarte, Tepedino (1999, p. 156), verifica a necessidade de abordar novas diretrizes para definir a ordem pública, analisando o direito infraconstitucional, sob a luz da Constituição, de forma a priorizar os valores não patrimoniais, com base na dignidade da pessoa humana, no desenvolvimento de sua personalidade, nos direitos sociais e na justiça distributiva, "para cujo atendimento, deve se voltar a iniciativa econômica privada e as situações jurídicas patrimoniais."

Ademais, Martínez (2004, 346-347) sustenta que:

Ese problema de límites, especialmente en las obligaciones y en los contratos, muy amparados en la libertad de sus cláusulas por la autonomía de la voluntad, dependerá del examen y de la ponderación non el caso concreto entre la autonomía de la voluntad y el presunto derecho aplicable. Habrá supuestos de una autonomía de la voluntad inmune a derechos, con lo que ésta será límite a su vez. Así no podrá argumentar la libertad de expresión para anular una cláusula que impida a un periodista trabajar, al tiempo colaborando en otra empresa periodística. ${ }^{8}$

Em consequência, Mendes (2012, p. 305) enfatiza que os direitos fundamentais devem ser vistos como princípios norteadores para que, então, o Estado possa ser obrigado a não apenas observar os direitos de todos os indivíduos, mas também a garantir ao cidadão a proteção contra as arbitrariedades de terceiros em geral, de maneira a materializar uma sociedade justa e igualitária, fundamentada na efetividade dos direitos fundamentais. Assim, quanto maior a desigualdade social entre os sujeitos, maior incidência terá tal aplicabilidade, de maneira a equilibrar as relações sociais e, evidentemente, do empregado em relação ao empregador.

\section{AÇÕES AFIRMATIVAS DA DIGNIDADE DA PESSOA HUMANA COMO UM MEIO DE RESISTÊNCIA: PONDERAÇÃO DE INTERESSES}

\footnotetext{
${ }^{8}$ Tradução Livre: Isso limita o problema, especialmente em obrigações e contratos, muito embora acerca da liberdade de cláusulas para a autonomia dependerá do exame e da ponderação no caso entre a autonomia e o suposto direito aplicável. Suposições que iram capacitar vontade imune a direitos, por isso vão ser apenas transformá-la. Então você não pode afirmar que a liberdade de expressão para substituir uma cláusula que impede um trabalho jornalista, colaborando na empresa jornalística outra. In: MARTÍNEZ, Gregoria Peces-Barba. Lecciones de Derechos Fundamentales. Madrid, Editorial Dykinson, 2004, pag. 346-347.
} 
A Constituição brasileira determina expressamente no art. 170 "que o poder econômico deve valorizar o trabalho humano; e seu objetivo precípuo é assegurar a todos existência digna conforme os ditames da justiça social." Nesse sentido, asseveramos em outro estudo (2009, p. 150) que:

Por tal razão, não é difícil constatar que o capital (ou o poder econômico) é o meio para assegurar e promover a dignidade do ser humano, sendo ilegítimo e inconstitucional qualquer raciocínio que pretenda inverter esta ordem, ou seja, colocar o homem como meio, como um mero fator de produção, para fomentar o capital, sem dele participar ou se beneficiar.

Dessa lógica decorre que a dignidade da pessoa humana, já minudentemente tratada nos primeiros capítulos da presente pesquisa, constitui o fundamento material e instrumental para desencadear ações legítimas de resistência contra a flexibilização nociva de direitos trabalhistas.

E é justamente a afirmação da dignidade da pessoa humana, que fundamenta os direitos trabalhistas, que proporcionará a tão almejada justiça social em nosso país, diminuindo a absurda e inaceitável desigualdade social e regional que exclui a grande massa dos cidadãos brasileiros do acesso aos meios básicos de vida digna, como o trabalho, a educação e a saúde.

Ademais, pretende-se por meio de ações afirmativas da dignidade da pessoa humana, promover a justiça social de forma a equilibrar a relação existente entre o empregador e o empregado, colocando o ser humano, e não o capital, como o núcleo do sistema.

Assim, trata-se de dar materialidade ao princípio em tela, de afirmá-lo no âmbito social e, com isso, de maneira reflexa, garantir proteção aos trabalhadores contra as mais diversas ameaças que possam estar sujeitos em face da relação jurídica subordinada que entabulam com o seu empregador.

Em outras palavras, cumpre-se dar força normativa e eficácia ao princípio da dignidade da pessoa humana, tanto na sua esfera defensiva, com o objetivo de proteger o trabalhador individualmente, como na sua dimensão prestacional, visando alcançar os meios necessários para que o trabalhador viva dignamente.

No mesmo sentido, enfatiza Delgado (2006, p. 91), que a dignidade humana, congloba "a dimensão social do indivíduo, uma vez que é inviável supor-se a presença do respeito a dignidade de um ser humano radicalmente excluído de qualquer inserção socioeconômica da sociedade."

Assim, a afirmação da dignidade da pessoa humana no núcleo social serve para que a ordem econômica não constitua um fim em si mesmo, devendo ser direcionada, isso 
sim, para promover e proteger o homem e sua dignidade, posto que, conforme Gemignani (2009, p. 49):

\begin{abstract}
O Estado pode, mas não pode tudo. As entidades coletivas podem, mas não podem tudo. As corporações podem, mas não podem tudo. As regras econômicas embasadas na necessidade/privação/escassez de meios podem, mas não podem tudo. Há um núcleo inalienável, que pertence a cada pessoa, sem o qual ela deixa de existir como sujeito de direitos e se transforma em súdito, um objeto a ser manipulado pelos desejos e interesses de outrem. É esse núcleo que os princípios preservam no mundo trabalho, independentemente de existir um vínculo de natureza empregatícia ou não.
\end{abstract}

É por esta razão que o empregador não possui poder diretivo supremo, visto que seu direito estende-se até o momento em que passa a adentrar na esfera jurídica do direito do trabalhador, no caso ora em apreço, sua privacidade e intimidade. Deste modo, conforme enfatiza Marmelstein (2013, p. 384-385), na casuística em concreto, haverá diversas situações que prejudicarão o auferimento de uma conciliação de interesses.

Isso se deve ao fato de que a proteção de determinado direito fundamental, inevitavelmente, acarretará a violação de outro bem jurídico protegido pela norma constitucional. É o que ocorre no caso do monitoramento dos empregados por câmeras, em consequência de que os interesses do empregador entram em choque com os direitos personalíssimos do trabalhador.

Neste caso, o juiz deverá efetuar um sopesamento de valores, que consiste em uma "atividade intelectual que, diante de valores colidentes, escolherá qual deve prevalecer e qual deve ceder", conforme denota Marmelstein (2013, p. 385). Assim, quando duas normas constitucionais colidirem, o juiz deve proceder com a verificação de qual norma em jogo possui menor densidade, para que ceda preponderância à outra, naquele caso em questão, fato este que consiste em afirmar, acerca da existência de uma hierarquia axiológica.

Ocorre, portanto, que apesar de os direitos fundamentais possuírem superioridade normativa, devido a sua posição privilegiada na Carta Magna, os mesmos, ainda assim, podem ser restringidos sempre que seu exercício compreenda ameaça de lesão de outros valores constitucionais.

Assim, convém salientar que, "limitar direitos não é apenas plenamente possível como muitas vezes necessário", conforme destaca Marmelstein (2013, p. 365-366). Porém, tal limitação apenas será legítima no caso de ser confirmada pelo teste da 
proporcionalidade. ${ }^{9}$ Dessa forma, sempre que a vontade do Judiciário for proteger ou preservar um dado valor constitucional, a limitação de direito colidente se faz plenamente aceitável.

O princípio da proporcionalidade tem pertinência fundamentada para que "nenhuma restrição a direitos fundamentais tome dimensões desproporcionais", no mesmo sentido, o respectivo autor enfatiza (2013, p. 367), que "verificar a proporcionalidade de uma medida que restringe determinado direito fundamental não é tão somente analisar se a medida é razoável. Trata-se, na verdade, de algo muito mais sofisticado e objetivo."

Destarte, convém destacar que tal princípio possui três dimensões, qual seja a adequação ou conformidade, a qual exige que o meio alcance a meta; a necessidade, que significa uma intervenção apenas nos limites necessários, de forma que constitua a mais amena de qualquer outro meio de atuação, conforme dispõe Alexy (2013, p. 118); e a proporcionalidade em sentido estrito, que conforme o respectivo autor, aufere qual dos méritos, abstratamente no mesmo nível, possui maior peso para o caso em epígrafe.

Na expressão de Alexy (2002, p. 82), as restrições aos direitos fundamentais ocorrem em consequências de regras ou princípios. No que tange aos princípios para alcançar uma restrição definitiva, se faz necessário que haja uma ponderação entre o direito fundamental em questão e ao princípio que o limita.

No que reporta a diferenciação entre os princípios da proporcionalidade e da razoabilidade, destaca-se que o primeiro surgiu nos Estados Unidos da América, enquanto o outro na Alemanha. No entanto, autores como Sarmento (2008, p. 87), salientam que mesmo "decorrentes de matrizes históricas diferentes, são, na prática, fungíveis, pois almejam o mesmo resultado: coibir o arbítrio do Poder Público, invalidando leis e atos administrativos [...] contrários à pauta de valores abrigada pela Constituição."

\footnotetext{
9 "O princípio ou máxima da proporcionalidade é, portanto, o instrumento necessário para aferir a legitimidade das leis e atos administrativos que restringem direitos fundamentais. Por isso, esse princípio é chamado de 'limite dos limites'. 'O objetivo da aplicação da regra da proporcionalidade, como o próprio nome indica, é fazer com que nenhuma restrição a direitos fundamentais tomem dimensões desproporcionais." MARMELSTEIN, George. Curso de direitos fundamentais. $4^{\mathrm{a}}$ Ed. São Paulo: Atlas 2013. P. 366.
} 
Em extensão, Guerra (2007, p. 70-71), expressa as considerações que deverão ser feitas pelos magistrados no momento de sopesar os princípios conflitantes ou normas colidentes:

a) o "peso abstrato" dos valores em conflito [...]; b) a interferência que a realização de um causa no outro e vice-versa (sic) a realização do segundo [...] causa no primeiro dos valores em conflito; c) quais as evidências disponíveis para fundamentar, racionalmente, as considerações relativas a b), uma vez que as afirmações produzidas quanto a este aspecto do problema - o grau de interferência -são afirmações descritivas, portanto [...] verificáveis, a exigir, em nome da racionalidade, o suporte de evidências empíricas.

No mesmo sentido, posiciona-se Sarmento (2008, p. 74):

A dignidade da pessoa humana afirma-se como o principal critério substantivo na direção da ponderação de interesses constitucionais. Ao deparar-se com uma colisão concreta entre princípios constitucionais, tem o operador do direito de, observada a proporcionalidade, adotar a solução mais consentânea com os valores humanitários que este princípio promove.

Ademais, como não há hierarquia entre princípios constitucionais, a solução de uma colisão entre eles dependerá de uma análise do caso concreto, no momento em que se for realizar a técnica da ponderação, onde que, em certos casos, o interesse coletivo pode justificar uma limitação proporcional a um direito fundamental, ao que Alexy (2013, p.114) salienta que não existe nenhum princípio soberano, pois, até mesmo o princípio da dignidade da pessoa humana encontra restrição frente a um direito social, que beneficie maior parte da sociedade. Nessa linha, Sarlet (2004, p. 136) enfatiza:

Assim, ainda que se possa reconhecer a possibilidade de alguma relativização da dignidade pessoal [...], não há como transigir no que diz com a preservação de um elemento nuclear intangível da dignidade, que justamente [...] consiste na vedação de qualquer conduta que importe em coisificação e instrumentalização do ser humano [...]. Da mesma forma, [...] com isto não se está a sustentar a inviabilidade de impor certas restrições aos direitos fundamentais, ainda que diretamente fundadas na proteção da dignidade da pessoa humana, desde que, à evidência, reste intacto o núcleo de dignidade destes direitos.

Ainda, de acordo com Alexy (2013, p. 141), outro limite que se impõe a ponderação de interesses compreende o respeito ao núcleo essencial de direitos fundamentais, isto é, um conteúdo mínimo destes direitos que são indisponíveis, e portanto, fora de limitação pelo legislador ou através do aplicador do Direito.

Desta forma Sarlet (2004, p. 200) enfatiza que a dignidade da pessoa humana sempre comporá um núcleo essencial de direitos fundamentais, pois qualquer atitude que venha a diminuir a aplicação da mesma ocorrerá irremediavelmente em desproporção, sendo considerada então, descabida. 
Outrossim, acerca da utilização de monitoramento por câmeras, utilizada pelo empregador como meio de fiscalizar o trabalho e obter maior produtividade do trabalhador e garantir a segurança do ambiente, constitui um meio que possui perfeita aceitação pela doutrina e jurisprudência, desde que, respeitando alguns limites, como a negação de instalação de câmaras em locais íntimos, como banheiros, refeitórios, vestiários, ou salas de descanso, com vistas a garantir que a intimidade e a privacidade do empregado sejam respeitadas.

Deve, então, haver sensatez e equilíbrio na utilização de tal aparato tecnológico, de maneira que não intervenha diretamente na privacidade do empregado. Dessa maneira, segundo Eberlin (2006, p. 94-95), o empregador deverá observar a razoabilidade na utilização da tecnologia e ainda dar ciência ao trabalhador que esta sendo filmado, bem como restringir a utilização de câmeras para os locais estritamente necessários, "há também, o entendimento de que a câmera não deve ficar focada apenas no posto de trabalho de um empregado (mas sim no ambiente como um todo), sob pena de vulnerar o seu direito à intimidade.”

De outra senda, como a utilização de câmeras consiste em ato lícito por parte do empregador, desde que respeitada à intimidade do empregado, a utilização das filmagens tem sido consideradas como prova lícita e hábil como forma de comprovar infrações disciplinares do empregado, podendo ensejar, inclusive, o rompimento do contrato de trabalho por justa causa do empregado.

No entanto, Silva Neto (2003, p. 82-83) salienta que a utilização de um monitoramento permanente sobre o meio ambiente pode causar condições adversas no empregado, não sendo por ele (o autor citado), considerada uma opção sadia, "fundamentalmente porque empregados e corpo discente monitorados permanentemente se tornam irritadiços e com a indisfarçável sensação de perda da própria individualidade."

No entanto, conclui-se pelo expendido nas linhas pretéritas o monitoramento por câmeras, desde que respeitados os limites da privacidade e intimidade do empregado é normalmente aceito tanto pela doutrina quanto pela jurisprudência, em virtude de que, a rigor, não há invasão ou arbitrariedade neste método, desde que respeitados os critérios de necessidade e razoabilidade enfatizados no presente estudo. 


\section{DA TEORIA À PRÁTICA: POSICIONAMENTO DOS TRIBUNAIS ACERCA DO MONITORAMENTO DO EMPREGADO POR CÂMERAS}

Conforme o exposto cumpre agora abordar alguns julgados para verificar o posicionamento dos tribunais brasileiros sobre a temática em foco. Assim, como pioneiro, destaca-se a decisão da Nona Turma do Tribunal Regional do Trabalho da Comarca do Rio de Janeiro, em que se admite a vigilância eletrônica (por meio de câmeras), no âmbito trabalhista, desde que respeitado os limites do poder diretivo do empregador, sendo que, de antemão, deverá ser avisado aos empregados para que os mesmos tenham ciência do que lhe estão submetendo, bem como, as câmeras não poderão estar focadas em um só ângulo, sob pena de ilicitude. Assim, dispõe o julgado:

CÂMERAS DE VÍDEO INSTALADAS EM VESTIÁRIO VOLTADAS PARA OS ARMÁRIOS. DANO MORAL. A vigilância eletrônica é admissível no ambiente de trabalho, desde que não extrapole os limites do poder diretivo do empregador. Todavia, cabe a este deixar claro para os empregados os ambientes que estão sendo monitorados, em respeito ao princípio da transparência. Não pode simplesmente alegar que as câmeras ficam voltadas para determinado lugar, como armários, por exemplo. Em se considerando que esse tipo de aparelho permite visão de $180^{\circ}$ a $360^{\circ}$, se a parte alegar como fato impeditivo que a área de visão não alcança todo o vestiário, é ônus desta comprovar as especificidades do produto, inclusive no que se refere ao ângulo e abrangência, porquanto é a única que possui condições de produzir tal prova. (TRT-1 - RO: 8745420115010225 RJ, Relator: Claudia de Souza Gomes Freire, Data de Julgamento: 15/01/2013, Nona Turma, Data de Publicação: 2013-01-24) (grifo nosso).

No mesmo sentido, merece referência a decisão da Primeira Turma do Tribunal Regional do Trabalho da...., alusivo ao uso de monitoramento por câmeras no ônibus, através da qual se pode constatar que o uso não apenas é permitido, como também é considerado necessário para fins de segurança, na medida em que "a adoção do mencionado dispositivo não invade a esfera de intimidade do empregado.” Ademais, o empregado já estava ciente do uso de tais aparelhos, cuja instalação, foi prevista precursoramente no edital de licitação, sendo então desconsiderado o abuso da conduta do poder diretivo e hierárquico do empregador. 
(...) Quanto às alegações referentes ao uso de câmera de monitoramento nos ônibus, são equipamentos cuja instalação já era prevista no edital de licitação para a concessão pelo poder público de exploração das linhas. Quanto ao uso adotado pelo empregador não só para fins de segurança, o que de resto não restou vulnerado com a prova testemunhal produzida, tem-se que a adoção de mencionado dispositivo não invade a esfera de intimidade do empregado. É colocado em ambiente de circulação aberto a empregados e usuários do serviço de transporte, qual seja, o interior do veículo de transporte de massa. O empregado sabe de sua existência, não sendo surpreendido com a produção de eventuais imagens. Demais disso, no uso do poder hierárquico e diretivo da atividade do empregado não aponta para a prática ora questionada como conduta abusiva do empregador por si só. Da mesma forma, eventuais prejuízos que invadam a esfera da personalidade do empregado deverão ser buscados em lides individuais, mediante cognição, não se verificando na esfera coletiva a confirmação das alegações contidas na exordial da presente ação civil pública.

(TRT-1 - RO: 00007933020115010056 RJ, Relator: Jose Nascimento Araujo Netto, Data de Julgamento: 11/03/2014, Primeira Turma, Data de Publicação: 28/04/2014) (grifo nosso).

Evidencia-se, portanto, que o monitoramento do empregado por câmeras é possível e permitido, não implicando em ofensa à intimidade ou à privacidade do empregado, desde que o meio em questão seja empregado sem abuso do poder diretivo, ou seja, subministrado pela proporcionalidade e razoabilidade, respeitando a dignidade humana do trabalhador.

\section{CONSIDERAÇÕES FINAIS}

De acordo com a pesquisa empreendida, constata-se que a dignidade humana compreende o princípio norteador de toda a órbita trabalhista, de forma a equilibrar a relação existente entre empregador e empregado.

Desta feita, percebe-se que ao empregador é garantido o direito ao poder diretivo, o qual, de acordo com a doutrina majoritária, emana do contrato de trabalho, ou seja, da autonomia de vontade entre as partes, no momento da celebração do contrato. Ocorre, porém, que ao contrário de outras concepções, tal tese não coaduna-se a ideia de poder 
soberano do empregador, na medida em que o poder diretivo encontra limites nos direitos fundamentais protetivos do empregado.

Assim, decorre que, por meio do uso do monitoramento por câmeras no ambiente de trabalho pode ocorrer uma suposta colisão entre o poder diretivo do empregador e o direito fundamental do empregado à privacidade e à intimidade, surgindo a necessidade de uma intervenção jurídica.

Nada obstante, tendo em vista que o impasse em comento carece de uma legislação reguladora, o problema acaba então sendo dirimido na esfera jurisdicional por meio de jurisprudências, e na esfera doutrinária, através das lições de balizados doutrinadores, cujo entendimento geral subentende que o uso de câmeras em um ambiente de trabalho é perfeitamente lícito objetivando proporcionar melhor fiscalização do ambiente laboral, desde que respeitados algumas diretrizes, v.g.: pré-avisar o empregado de que o ambiente está sendo monitorado por câmeras; não colocá-las em salas de descanso ou em banheiros, etc.

Ademais, respeitados os limites da proporcionalidade e da razoabilidade dentro da esfera trabalhista, torna-se não apenas lícita, como necessária a utilização de tais meios como forma de fiscalização e controle do ambiente de trabalho.

\section{REFERÊNCIAS}

ALEXY, Robert.A existência dos direitos humanos. In: Níveis de efetivação dos direitos fundamentais civis e sociais: um diálogo Brasil e Alemanha. ALEXY, Robert ...[et al.] (orgs). Joaçaba: EditoraUnoesc, 2013. Press, 2002.

A theory of Constitutional Rights. Trad. Julian Rivers. Oxford University

BARROS, Alice Monteiro de. Poder hierárquico do empregador. Poder diretivo. In: Curso de Direito do Trabalho: estudos em memória de Célio Goyatá. BARROS, Alice Monteiro de (Coord.). 3 ed. rev., atual. eampl. São Paulo: LTr, 1997, p. 557-576.

BARBAGELATA, Hector-Hugo. EI particularismo delderechodeltrabajo. Montevideo/Uruguai: Fundacíon de Cultura Universitaria, 1995

BRASIL. Consolidação das Leis do Trabalho, 1943. 18.ed. São Paulo: Rideel, 2012. -. Constituição da República Federativa do Brasil, 1988. 15.ed. São Paulo: Rideel, 2009. 
. Acórdão do Tribunal Regional do Trabalho. CÂMERAS DE VÍDEO

INSTALADAS EM VESTIÁRIO VOLTADAS PARA OS ARMÁRIOS. DANO

MORAL. Acórdão. TRT-1 - RO: 8745420115010225 RJ. Relator: Claudia de Souza

Gomes Freire, Data de Julgamento: 15/01/2013, Nona Turma, Data de Publicação:

2013-01-24.

Acórdão do Tribunal Regional do Trabalho. TRT-1 - RO:

00007933020115010056 RJ, Relator: Jose Nascimento Araujo Netto, Data de

Julgamento: 11/03/2014, Primeira Turma, Data de Publicação: 28/04/2014.

CASTILHO, Ricardo. Direitos humanos, vol. 30,. — São Paulo: Saraiva, 2011.

DELGADO, Maurício Godinho. Capitalismo, trabalho e emprego: entre o paradigma da destruição e os caminhos da reconstrução. São Paulo: LTr, 2006.

. Proteção à intimidade do empregado. São Paulo: LTR, 1997.

Curso de direito do trabalho. 5 ed. São Paulo: LTr, 2006.

DWORKIN, Ronald. Uma questão de princípio. Trad. Luís Carlos Borges, 2 ed. São Paulo, Martins Fontes, 2005.

EBERLIN. Fernando Büscher Von Teschenhausen. Poder de direção versus direito à privacidade do empregado. Revista IOB Trabalhista e Previdenciária, São Paulo, v. 17, n. 205, jul. 2006.

GEMIGNANI, Tereza Aparecida Asta; GEMIGNANI, Daniel. A eficácia dos direitos fundamentais nas relações de trabalho. Revista do Tribunal Regional do Trabalho da $3^{\text {a }}$ Região. Minas Gerais. ISSN 0076/8855. n.80, jul/dez. 2009.

GOLDSCHMIDT, Rodrigo. Flexibilização dos direitos trabalhistas: ações afirmativas da dignidade da pessoa humana como forma de resistência, São Paulo, LTr, 2009.

GRANDI, Mario. El trabajo no es uma mercancia: reflexiones akmargen de uma formula para volver a meditar. In: Estúdios em homenajeal Prof. Héctor-Hugo Barbagelata. Montevideo-Uruguai: Fundación de Cultura Universitária, 1997.

GUERRA, Sidney. Hermenêutica, ponderação e colisão de Direitos Fundamentais. Lumen Juris, 2007.

HOOFT, Pedro Federico. Bioética y derechos humanos. $1^{\text {a }}$ ed. Buenos Aires: Depalma, 2004.

LENZA, Pedro. Direito Constitucional Esquematizado. 15 $5^{\text {a }}$ edição. São Paulo: Saraiva, 2011.

MARTÍNEZ, GregoriaPeces-Barba. Lecciones de DerechosFundamentales. Madrid, Editorial Dykinson, 2004.

MARMELSTEIN, George. Curso de direitos fundamentais.4 ed.. São Paulo: Atlas, 2013. 
MALLET, Estêvão. Direitos de personalidade e Direito do Trabalho. Revista LTr, São Paulo, v. 68, n. 11, nov. 2004.

MARTINS, Ives Gandra da Silva, MENDES, Gilmar Ferreira, NASCIMENTO, Carlos Valderdo. Tratado de direito constitucional, Vol. 1, 2. ed. - São Paulo : Saraiva, 2012.

MENDES, Gilmar Ferreira, BRANCO, Paulo Gustavo Gonet. Curso de direito constitucional. 7. ed. rev. e atual. - São Paulo: Saraiva, 2012.

MILL, Stuart. Sobre a liberdade.São Paulo: Escala. 2006.

MORAES, Alexandre. Direitos humanos fundamentais: comentários aos arts. $1^{\circ}$ ao $5^{\circ}$ da Constituição da República Federativa do Brasil. São Paulo: Atlas, 2013.

NASCIMENTO, Amauri Mascaro. Curso de direito do trabalho, $18^{\text {a }}$ Ed. São Paulo, Saraiva, 2003.

PEREIRA, Jane Reis Gonçalves. Apontamentos para a aplicação das normas de direito fundamental nas relações jurídicas entre particulares. In: BARROSO, Luís Roberto (org.). 2 ed. rev. e atual. Rio de Janeiro: Renovar, 2006.

SARLET, Ingo Wolfgang. Dignidade da pessoa humana e direitos fundamentais. $3^{\text {a }}$ ed. Porto Alegre, Livraria do Advogado, 2004.

SARMENTO, Daniel. Direitos Fundamentais e Relações Privadas. 2. ed. Rio de Janeiro, Lumen Juris, 2008.

SILVA, Érica Guerra da.Os entraves para o desenvolvimento da função social da empresa. Revista de Direito Brasileira. SILVEIRA, Vladimir Oliveira da (Coord.). Florianópolis. ISSN 2237-583X. ano 3, vol. 6. set.dez./2013.

SILVA NETO, Manoel Jorge e. Direito à intimidade do empregado e câmeras de televisão. Gênesis, Curitiba, n. 22, jul. 2003.

SIMÓN, Sandra Lia. A proteção constitucional da intimidade e da vida privada do empregado. São Paulo: LTr, 2000.

SZANIAWSKI, Elimar. Direitos de personalidade e sua tutela. São Paulo: Revista dos Tribunais, 1993.

TEPEDINO, Gustavo. A tutela da personalidade no Ordenamento Civilconstitucional Brasileiro. In: TEPEDINO, Gustavo. Temas de Direito Civil. Rio de Janeiro: Renovar, 1999.

TRAMONTINA, Robison, HAHN, Paulo. A noção Kantiana de "dignidade humana". In: Níveis de efetivação dos direitos fundamentais civis e sociais: um diálogo Brasil e Alemanha. ALEXY,Robert ...[et al.] (orgs). Joaçaba: Editora Unoesc, 2013. 